\title{
The achieving with integrity seminar: an integrative approach to promoting moral development in secondary school classrooms
}

\author{
Jason M. Stephens ${ }^{1 *}$ and David B. Wangaard ${ }^{2}$
}

\author{
* Correspondence: \\ jm.stephens@auckland.ac.nz \\ ${ }^{1}$ The University of Auckland, \\ Auckland, New Zealand \\ Full list of author information is \\ available at the end of the article
}

\begin{abstract}
For anyone concerned about students' moral development, academic dishonesty presents a pervasive problem but also a promising possibility. The present paper describes the theoretical and empirical underpinnings of process-oriented, fourcomponent model approach to promoting students' "moral functioning" related to academic integrity, and the research project currently underway that is providing Web-based professional development to teachers for using the model in their high school classrooms. In doing so, we hope to develop a scalable approach that offers teachers an opportunity to be the primary agents of change in transforming the problem of academic dishonesty into a possibility for positive youth development.
\end{abstract}

Keywords: Moral development, Character education, Academic integrity, Secondary schools, Professional development

For anyone concerned about students' moral development, academic dishonesty represents a pervasive problem but also a promising possibility. Paradoxically, it is the pervasiveness of academic dishonesty, in part, that produces the possibility. More concretely, it is because the majority ${ }^{1}$ of secondary and tertiary students have admitted to cheating (Josephson Institute of Ethics, 2012; Lupton \& Chapman, 2002; Ma, McCabe, \& Liu, 2013; McCabe, 2005; Rawwas, Al-Khatib, \& Vitell, 2004; Stephens, Romakin, \& Yukhymenko, 2010) - many despite believing that it is wrong (e.g., Anderman, Griesinger, \& Westerfield, 1998; Jensen, Arnett, Feldman, \& Cauffman, 2002; Jordan, 2001; Stephens \& Nicholson, 2008) or that it "hurts your character" (Josephson Institute of Ethics, 2012) - that it is such a potentially powerful lever for fostering their moral development.

It is with this sense of possibility in mind that we developed the Achieving with Integrity (AwI) Seminar. The AwI Seminar is special, if not unique, among character education programs in its focus on promoting academic integrity and using the problem of cheating as opportunity for positive youth development (e.g., Berkowitz, Sherblom, Bier, \& Battistich, 2006; Damon, 2004). Specifically, rather than focus on the behavior of cheating as the sole dependent variable, and intervening with punishment (or other forms of externally-regulated control) to reduce it, the AwI Seminar focuses on "achieving with integrity" as the goal, and seeks to reach this goal by strengthening positive "developmental assets" (Benson, Scales, Hamilton, \& Sesma, 2006). In the AwI

(c) The Author(s). 2016 Open Access This article is distributed under the terms of the Creative Commons Attribution 4.0 International License (http://creativecommons.org/licenses/by/4.0/), which permits unrestricted use, distribution, and reproduction in any medium, provided you give appropriate credit to the original author(s) and the source, provide a link to the Creative Commons license, and indicate if changes were made. 
Seminar, the positive "assets" to be developed are the perceptual, cognitive, motivational, and behavioural processes associated with the four component model (FCM) of moral functioning (Rest, 1986; Rest, Narvaez, Bebeau, \& Thoma, 1999).

In this paper, we describe the FCM in greater detail and how (and why) it serves as the primary theoretical framework undergirding the AwI Seminar. We also describe the AwI Seminar itself-the core questions, goals and objectives, key concepts, and instructional activities associated with each of the four major "discussions" that comprise the Seminar. We then provide an overview the teacher professional development program we created to prepare teachers to integrate the AwI Seminar in their classroom as well as results from a fidelity of implementation study of teachers who completed the program. In doing so, we hope this paper not only offers a problem-based, theoretically-grounded approach to promoting moral development but also a viable teacher professional development program needed to support its prescribed implementation in secondary classrooms.

\section{The four-component model of moral functioning}

The development of AwI Seminar was informed by many theories related to morality (e.g., Bandura, 1986; Beck \& Ajzen, 1991; Haidt, 2001; Kohlberg \& Candee, 1984; Nucci, 1994; Smetana, 2006; Turiel, 1983), but primarily so by Rest's four-component model (FCM) of moral functioning (Rest, 1986; Rest et al., 1999). The FCM postulates that effective moral functioning involves the integrated use of at least four processes each involving a subset of skills or abilities. In this section, we describe each of the four components and how they relate to moral functioning in the domain of academic integrity.

\section{Moral awareness}

Also called moral sensitivity, moral awareness involves the capacity to perceive the moral dimensions of a given situation and the ability to anticipate and interpret how others might be feeling or react in that situation (Rest, 1986; Rest et al., 1999). For example, a student might see the request of a friend to copy her test as an issue involving moral values such as fairness, honesty or loyalty, or she may not. Instead, she may see such behavior as a personal or conventional issue: that is, affecting only herself or merely violating an arbitrary social rule (for more on these domain distinctions, see Nucci, 1994). Many high school students do not see the moral dimensions of academic dishonesty, and simply think of cheating as a personal choice that only harms oneself (Schab, 1991). Such a failure to perceive the moral dimensions of academic dishonesty affects the engagement of the remaining three components.

\section{Moral judgment}

Moral judgment encompasses the capacity to reason morally and render judgments about which course of action would be morally right or best (in the event of a moral dilemma involving the competing of two or more values or principles). Consistent with the cognitive-development tradition in moral psychology (Kohlberg, 1969; Piaget, 1932), Rest et al. (1999) postulate that there are three "developmental schemas" associated with moral thinking: the Personal Interest schema (which is normative during childhood and justifies moral choices in terms of the personal costs and benefits), the 
Maintaining Norms schema (which matures during adolescence and justifies moral choices in terms of the maintenance of "established social order"), and the Postconventional schema (which emerge in adolescence and justifies moral choices in terms of "shared ideals" that are "fully reciprocal") (pp. 4-6).

In terms of academic dishonesty, a student may think cheating is the "wrong" thing to do because 1) she might get caught and punished, 2) it is against the school rules, or 3) it violates shared ideals or moral principles such as honesty, fairness and reciprocity. While all three are valid reasons or justifications for deciding that academic cheating is morally wrong, the goal of the AwI Seminar is to help develop students' use of (and even preference for) the Postconventional schema. Existing experimental research has shown that this schema (or "principled reasoning" as operationalized in these studies) is negatively associated with cheating behavior, but only when the threat of getting caught is high (Leming, 1978; Malinowski \& Smith, 1985). Similarly, while students' judgments related to the wrongness of cheating have been negatively associated with cheating, many students report doing it anyway (e.g., Anderman et al., 1998; Jensen et al., 2002; Jordan, 2001; Stephens \& Nicholson, 2008).

In short, while moral judgment may be a necessary component of moral functioning, it alone is not sufficient for ensuring moral action. Moral motivation and commitment are needed as well.

\section{Moral commitment}

Moral commitment was originally called moral motivation by Rest (1986) and involves the desire and will to act on one's moral judgments. Following Kohlberg (Kohlberg \& Candee, 1984), this process involves making a "responsibility judgment" (e.g., "I'm responsible for not cheating") that complements the "deontic judgment" described above (e.g., "It's morally wrong to cheat"). So, while many students may judge cheating to be morally wrong, they don't always judge themselves to be personally responsible for acting in accord with that judgment.

Numerous empirical studies have employed Beck and Azjen's (1991) concept and measure of "moral obligation" (akin to "responsibility judgment") and found strong negative relations between students' moral obligation and academic dishonesty (e.g., Beck \& Ajzen, 1991; Harding, Carpenter, Finelli, \& Passow, 2004; Stephens, Young, \& Calabrese, 2007). However, research has also shown that this sense of moral control and personal responsibility can be "neutralized" (Sykes \& Matza, 1957) or "disengaged" (Bandura, 1986, 1990) through various types of "mechanisms," such as externalizing blame or minimizing the wrongdoing: The more students tend to neutralize or disengage responsibility for cheating behavior the more likely they are to engage in it (Diekhoff et al., 1996; Haines, Diekhoff, LaBeff, \& Clark, 1986; Jensen et al., 2002; McCabe, 1992; Shu, Gino, \& Bazerman, 2011; Stephens \& Gehlbach, 2007; Stephens et al., 2007).

The AwI Seminar seeks to strengthen students' motivation and commitment to academic integrity by increasing their responsibility judgements (i.e., the extent to which believe they are personally responsible for refraining from engagement in various forms of academic dishonesty) and decreasing their tendency to disengage that sense of responsibility. Both are essential for moral action. 


\section{Moral action}

Moral action or behavior entails the following through living out - through word and action - of one's moral judgments and commitments. Doing so involves both will and skill-"the necessary ego strength and implementation skills to complete the action despite obstacles, opposition, and fatigue" (Narvaez, 2009, p. 11). To date, there has been little empirical investigation on the role of either will or skill related to academic integrity. With respect to the former, our review of literature turned up only one study involving ego-strength (Perry, Kane, Bernesser, \& Spicker, 1990), which was negatively associated with cheating. However, similar constructs such as self-control has also proven to be negative predictors of cheating (Bolin, 2004; Grasmick, Tittle, Bursik, \& Arneklev, 1993) while constructs such as impulsivity, the obverse of ego-strength, have proved positive predictors of cheating (e.g., Anderman, Cupp, \& Lane, 2009).

Research related to "implementation skills" is even more scant, though that is likely to change soon as many colleges and universities in the US and elsewhere are beginning to require their students to undergo academic integrity training (usually in the form of completing an online tutorial program). A field experiment involving one such program-aimed at reducing plagiarism through promoting students' understanding of plagiarism and effective strategies for avoiding plagiarism-yielded significant positive effects: students who completed the Web-based tutorial engaged in significantly less plagiarism (Dee \& Jacob, 2010). In a similar vein, Jackson (Jackson, 2006) used an interactive, Web-based tutorial to produce significant gains in undergraduates understanding of concepts like plagiarism and paraphrasing.

In short, both will and skill are needed for moral action and the AwI Seminar seeks to strengthen students' ego-strength and to equip them with non-moral knowledge and skills needed to carry out their moral commitments.

\section{A FCM of moral functioning in the domain of academic integrity}

As suggested by the word "integrated" in Rest et al. (1999), the four components described above are not theorized to operate in a linear or chronological manner (awareness first, then judgment, then commitment, and finally action), the reality is that perception, cognition, motivation and behaviour interact - with each other and all together - in a complex set of reciprocal relationships. Nonetheless, the representation of the four components as a linear relationship is not entirely disingenuous. Our phenomenological reality, or lived experience, often follows the pathway depicted in Fig. 1 below: first, we perceive a situation (noticing, or not, the moral values or principles that

\begin{tabular}{|c|c|c|c|}
\hline $\begin{array}{l}\text { Awareness } \\
\text { (Notice) }\end{array}$ & $\begin{array}{c}\text { Judgment } \\
\text { (Think) }\end{array}$ & $\begin{array}{c}\text { Commitment } \\
\text { (Aim) }\end{array}$ & $\begin{array}{l}\text { Action } \\
\text { (Act) }\end{array}$ \\
\hline $\begin{array}{c}\text { Schematic } \\
\text { "Cheating has } \\
\text { moral } \\
\text { implications." }\end{array}$ & $\begin{array}{l}\text { Principled } \\
\text { "Cheating is } \\
\text { morally } \\
\text { wrong." }\end{array}$ & $\begin{array}{c}\text { Engaged } \\
\text { "It's my } \\
\text { responsibility' } \\
\text { not to cheat." }\end{array}$ & $\begin{array}{l}\text { Integrity } \\
\text { "I did not } \\
\text { cheat." }\end{array}$ \\
\hline $\begin{array}{c}\text { Aschematic } \\
\text { “Cheating } \\
\text { does not have } \\
\text { moral } \\
\text { implications." }\end{array}$ & $\begin{array}{l}\text { Conventional } \\
\text { "Cheating is } \\
\text { not morally } \\
\text { wrong." }\end{array}$ & $\begin{array}{l}\text { Disengaged } \\
\text { "It's not my } \\
\text { responsibility." }\end{array}$ & $\begin{array}{l}\text { Dishonesty } \\
\text { "I cheated." }\end{array}$ \\
\hline
\end{tabular}


may be at stake); then we think about it (using our moral reasoning - weighing competing values or principles - to render a judgment concerning the right course of action); then the moral self is engaged (affective and cognitive motivational systems are activated as we commit ourselves to enacting the right course of action); and, finally, our character must be strong to act morally (we must possess both the moral egostrength or will needed to overcome barriers in pursuit of the chosen action and the non-moral knowledge and skills needed to perform it).

As illustrated by lines in Fig. 1, there is only one pathway to academic integrity but many pathways to academic dishonesty. To be clear, academic integrity as conceptualized here requires more than the absence of cheating; one, that is, must refrain from cheating because one notices that it involves moral issues (e.g., fairness, duty, harm, etc.) thinks that it is morally wrong (because it is unfair, violation of duty, harmful, etc.), and feels personally responsible for refraining from cheating. In other words, there must be an integration of all four components of moral functioning. As detailed above, this moral "high road" appears to be the road less traveled among high school and university students as most report cheating (e.g., Josephson Institute of Ethics, 2012; McCabe, 2005). As depicted by the dashed lines, defections off the high road can occur throughout the process-not noticing that one is in a moral situation, not thinking that cheating is morally wrong, or not feeling responsible for your cheating even if you believe it wrong.

Using this adaptation of the FCM of moral functioning as our conceptual framework for understanding academic integrity and dishonesty, we have developed the AwI Seminar for students. As described below, the AwI Seminar seeks to engage students in a series of four discussions of "core questions" related to each of the four components of moral functioning. In doing so, the AwI Seminar hopes to strengthen the knowledge and skills that students need to travel the high road and prevent the kind of deflections that lead to the low road.

\section{The achieving with integrity seminar for students}

As described above, the primary goal of the AwI Seminar is not simply to reduce academic dishonesty, but rather to develop students' moral functioning by increasing knowledge and skills associated with greater moral awareness, judgment, commitment and action. The AwI Seminar attempts to achieve this goal by engaging students in a series of discussions related to ethics and integrity. As suggested by the use of the term "discussions," the AwI Seminar is not meant to be delivered as a lecture (whereby the teacher transmits the "facts" to be learned and inculcates the values to be internalized). Rather, in a manner consistent with the principles of social constructivism, the AwI Seminar is designed to unfold as a dialogue about a contemporary "real world" challenge (i.e., achieving with integrity in a culture of cheating). In this dialog, the teacher's role is that of an "expert learner" and facilitator - poising questions and creating opportunities for individual reflection and social "problem-solving" with an emphasis on conceptual understanding and higher order thinking skills.

In order to initiate the dialog related to achieving with integrity and its importance, the AwI Seminar begins by asking students to consider either hypothetical or actual cases involving academic dishonesty. Among the recources provided to teachers who complete our professional development program is a file of numerous "Cases for 
Consideration." Several of these cases are drawn from newspaper headlines and offer real-world examples of academic dishonesty in high profile places (e.g., Barnard \& Newcomer, 2012; Perez-Pena \& Bidgood, 2012). The remaining cases are hypothetical ones that present a student caught in moral dilemma-a situation where competing goals and values are pulling her in different directions. Here's an example of a hypothetical case:

Laura is a very bright student. Everyone knows she very smart, and her teachers often point her out as a "model student." Her reputation, however, sometimes causes unwelcomed attention and difficult choices. Here's an example: After taking an important test in [science, history, etc.] class, one of Laura's friends stops her in the hall and starts grilling her about the test. The friend is taking the test later that day and she wants Laura to tell her all of the test questions and answers that she can remember. Laura feels torn and doesn't know what to do.

In the AwI Seminar teachers use cases like the one above as an "anchor" (Bransford, Sherwood, Hasselbring, Kinzer, \& Williams, 1990) for initiating and sustaining individual reflection and group dialog over the course of the four discussions. Each discussion was designed to be implemented within a 50 min time period, the traditional length of secondary classes (ages 13 to 17) in the US. As detailed below, each of the discussions consist of four major components: first, a pair of "core questions" that are designed to initiate the discussion; second, a description of the "goals and objectives" associated with the discussion; third, a set of "key concepts" that provide a language or framework for deepening the discussion; and fourth, a "primary activity protocol" that guides participants with a series of process steps for thinking through the core questions. We developed the latter-the four activity protocols described below-based on the process steps suggested by Narveaz in her adaption of the FCM for Nurturing Character in the Classroom (Narvaez \& colleagues, 2009), a four-volume series with each volume focused on one of the four components.

\section{Discussion One on moral awareness}

\section{Core questions}

What's "moral"? Is this a moral situation?

\section{Goals and objectives}

As suggested by the two core questions, the overarching goal of the first discussion is to engage students in dialogue about the meaning of the word "moral" and how one might ascertain if a given situation is a "moral situation." The specific learning objectives include 1) developing students' understanding of the term "moral" and 2) increasing their ability to notice the moral dimensions of a given situation.

\section{Key concepts}

Answering the first core question and deciding what's "moral" is arguably the most controversial part of the AwI Seminar. In a diverse, multicultural democratic societies with strong civil liberties and freedom of religion, a highly inclusive and pluralistic conception of morality is perhaps the most acceptable and useful. Haidt's (Haidt, 2013; Haidt \& Joseph, 2004) moral foundations theory offers such a conception of morality. 
Grounded in research from various fields of study-cultural psychology, neuroscience, and primatology-Haidt posits the existence of (at least) six "intuitive ethics" that we call "core values": fairness, care, liberty, loyalty, authority and sanctity. These ethics are thought to be innate, but not necessarily "expressed by all people or cultures" as "experience can suppress, alter or magnify the importance of a foundation" (Haidt, 2013, p. 290). In other words, based on cultural, religious and even political affiliations, people vary in the extent to which they recognize and value a given foundation as a moral concern (Haidt \& Graham, 2007; Haidt \& Joseph, 2004; Shweder, Mahapatra, \& Miller, 1987). Although still controversial (e.g., Maxwell \& Beaulac, 2013), Haidt's inclusive and pluralist conception of morality offers a robust framework and set of key concepts (the six "intuitive ethics") needed for a meaningful discussion of the core questions.

\section{Primary activity protocol}

Based on the suggested activities offered by Narvaez and Endicott (2009) we develop the Analysis of Moral Awareness Protocol (AMAP). As with the remaining three activity protocols described below, the AMAP is designed to stimulate students' seeing and thinking related to the moral dimensions or values inherent in a given situation. Specifically, the AMAP focuses on three sub-components or processes related to moral awareness that teachers can develop by engaging students in activities and discussions that help them do the following:

A. Notice the Problem

- What kind of problems or issues are present in this situation? Are there moral values or ethics present?

B. State the Situation

- What is the problem? How did it come about?

C. Identify the Interested Parties

- Who's involved? Who are the people who are affected?

These three questions are provided to guide discussion one and help students determine, "Is there a moral situation here?" based on their analysis of the circumstances in light of a compromise of any of Haidt's core values. If an ethical circumstance is identified, the students can proceed to Discussion Two.

\section{Discussion Two on moral judgment}

Core questions

What's "right"? What should one do in this situation?

\section{Goals and objectives}

The overarching goal of this discussion is to enhance students' capacity for moral reasoning and judgment related to academic integrity. The specific learning objectives include increasing students' 1) capacity to understand and differentiate among the three schemas of moral reasoning (Personal Interest, Maintaining Norms, and Postconventional), and 2) use of and preference for Postconventional reasoning in the making of moral judgments related to academic dishonesty (e.g., "It's wrong because it's not fair to others" as opposed to "It's wrong because I might get caught and punished"). 


\section{Key concepts}

As indicated in the objectives, the key concepts associated with this discussion of moral judgment are Rest et al.'s (2000) three "developmental schemas": Personal Interest (PI), Maintaining Norms (MN) and Postconventional (PC). Students should not only come to understand the basis of moral thinking associated with each schema, but also their developmental sequence. While all three may be the basis for making moral judgments, the Postconventional schema is the most developmentally mature schema and Personal Interest the least so. In relation to protocol described below, it is suggested that teachers introduce these three developmental schemas after students have completed the first three steps of the following activity protocol.

\section{Primary activity protocol}

Based on the suggested activities offered by Narvaez and Bock (2009) we develop the Ethical Decision Making Activity (EMDA). The EDMA provides teachers and students with a multiple step process for taking stock of a moral situation and rendering a moral judgment about how one should proceed and why. As detailed below, the first three steps (A-C), and the last one (G), should be completed individually and steps D thru F have been designed for students to complete in small groups:

\section{Part I: Individual Reflection}

A. List: Possible Courses of Action and their Consequences

- What are the possible courses of action one might take in this situation? What are the consequences (positive and negative) of each potential action and the core value demonstrated for each action?

B. Decide: Make a Moral Judgment

- What's the right thing to do? After weighing the options identified above, what should one do in this situation? What core values should be prioritized?

C. Explain: Describe Your Reasoning

- Why should one do what you've decided? What reasons or type of reasoning justify the course of action you chosen?

Part II. Small Group Discussion

D. Share: Exchange Ideas with Peers

- Students take turns sharing with moral judgments and the reasoning behind them. [Note: the EDMA provides a chart for completing this process and the one below.]

E. Dissect: Analyze Your Ideas

- Students use their collective understandings of the six core values and three lenses of moral reasoning to analyze the reasoning behind each judgment shared above; classifying each judgment as a product of or rooted in one of the three developmental schemas.

F. Evaluate: Render a Revised Judgment

- Using your shared understandings of the situation at hand, and the reasoning behind (as well as consequences of) various possible action choice, what does your group think is the "right" thing to do in this situation? What core values should be prioritized? Why? 


\section{Part III: Individual Reflection}

G. Reflect: Look Back and Learn

- Look back to your first judgment and the reasoning behind it (Step A-C). Has either changed? If so, how so? If not, why not?

Completing the final individual reflection prepares the students to move to Discussion Three.

\section{Discussion three on moral commitment}

\section{Core questions}

Why be "good"? Am I responsible for doing the right thing?

\section{Goals and objectives}

Fostering students' motivation for and commitment to doing the "right"; taking personal responsibility for acting on one's judgment; prioritizing the principled path over the expedient one.

\section{Key concepts}

The key concepts associated with the objectives of this discussion include Kohlberg and Candee's (1984) "responsibility judgment" and several of Bandura's (1986) "mechanisms of moral disengagement." As defined and distinguished by Kohlberg and Candee's (1984), a "deontic judgment" is as a "first-order" judgment concerning the rightness or wrongness of given action (i.e., what "one" should do) while a responsibility judgment is a "second-order affirmation of the will to act in terms of that judgment" (p. 57). These responsibility judgments, however, can be undermined by the activation of psychological mechanisms that serve to disengage one's sense of obligation or culpability (Bandura, 1986, 1990, 1999). In the AwI Seminar, students are asked to consider two types of such mechanisms and examples of the rationalizations associated with them: 1) "externalizing blame," which can be accomplished through the displacement of responsibility (e.g., "It's the teachers fault") or diffusion of responsibility (e.g., "Everybody does it"), and 2) "minimizing the wrong" through euphemistic labeling (e.g., "I only fudged a few numbers") or palliative comparison (e.g., "I just cheated on a test, it's not like I committed murder!").

\section{Primary activity protocol}

Based on the suggestions of Narvaez and Lies (2009) we develop the Values Inventory and Prioritization Activity (VIPA). The VIPA involves three steps that should be completed individually by all students, but also discussed in either small or large group discussion facilitated by the teacher.

\section{A. Decide: Make a Responsiblity Judgment}

- Am I responsible? What should I do in this situation?

B. Confirm: Prioritize Values

- What goals, core values, or ethics does your decision prioritize and uphold? What goals, values, or ethics are sacrificed? 


\section{Check: Expose Rationalizations}

- Is your chosen course of action free of rationalizations? Have you used any "mechanisms" to disengage your sense of moral responsibility?

The goal of this third discussion is to focus students on their choice of personal responsibility and commitment to demonstrate core values. Discussion Four will now be introduced to help students act on their commitment.

\section{Discussion four on moral action}

\section{Core questions}

How do I do it? What kind of "will and skill" will be needed?

\section{Goals and objectives}

The primary goal of this discussion is to develop students' "will and skill" related to academic integrity. The specific objectives include increasing students': 1) academic skills, such as a) effective note-taking skills, b) project planning and time management skills, c) test preparation and test taking strategies, d) techniques for paraphrasing the work of other and for quoting it directly, and e) the proper citation style for your subject area (e.g., MLA, Chicago, APA, etc.); 2) social skills, such as the capacity to effectively reframe requests for unpermitted assistance or refusing such requests diplomatically or non-verbally where possible; and 3) intrapersonal will-i.e., the "ego-strength" to resist temptation and persevere in the face of obstacles.

\section{Key concepts}

The key concepts associated with this discussion concern ideas associated the types of skills needed to carryout moral judgments and commitments as well as the will needed to do so. As such the goals and objectives are less focused on conceptual understanding (though students need to understand such concepts as "intellectual property", "plagiarism", and "paraphrasing") and more focused on the skills (both academic and social) needed to enact one's commitment. These skills, and the will to enact them, are described above in three objectives for this discussion.

\section{Primary activity protocol}

Based on the suggested activities offered by Narvaez (2009) we develop the Skill and Will Action Protocol (SWAP). The SWAP is designed to help students account for the types of skills and will that will be needed to carryout the responsibility judgments they made during the previous discussion.

\section{A. Employ Academic Skills}

- What academic skills will you need to do the act on your commitment?

B. Deploy Social Skills

- What social skills will you need to do the act on your commitment?

C. Exercise the Will

- Doing the right thing is not always easy. How will you remain ethical if challenged? 
Implemented in sequence, the four discussions suggested here strengthen a student's (1) moral awareness and identify a moral problem and who is involved, (2) moral judgment to analyze a moral problem and determine action options, consequences for those actions, the core values demonstrated in actions and the best ethical action by prioritizing morally principled ethical actions, (3) moral commitment by identifying and resisting rationalizations to support a personal commitment to demonstrating core values, and (4) moral action through the anticipation and development of skills and will in support of moral commitment.

\section{Preparing teachers to use the achieving with integrity seminar: a fidelity of implementation study}

In order to bring the AwI Seminar to fruition, we developed a teacher professional development program designed to prepare teachers to use the Seminar in their classrooms. Unlike traditional, "one-shot" teacher PD programmes, which have been roundly (and rightly) criticized as largely ineffectual, the AwI teacher PD program incorporates researched-based PD practices (e.g., Quint, 2011). These practices include supplementing the use of whole group tutorials and discussions (with teachers across schools) with the use of small team meetings (among teachers at the same school) as well as classroom observations and coaching. Specifically, the AwI teacher PD program comprised: 1) a series of five biweekly seminars (mirroring the structure of the AwI Seminar for students); 2) weekly school-based team meetings preceding and during implementation of the Seminar; and 3) two classroom observations by research staff during implementation, each combined with one-on-one, post-observation coaching.

With the support of external funding, we conducted a fidelity of implementation study to assess the extent to which teacher participation in the PD program resulted in the prescribed use AwI seminar in the classroom. Before turning to the Methods, Results, and Discussion of this study, it's important to note a final objective of the grant we received: the development and validation the various instruments needed to conduct an effectiveness study related to student outcomes (for details, see the Goals and Objectives sub-sections for each Discussion). While the activities protocols described above (i.e., the AMAP, EDMA, VIPA, and SWAP) could be part of such a study, additional measures would be needed. Toward that end, we created several original measures and adapted several existing ones, including Beck and Ajzen's (1991) moral obligation scale, Bandura et al.'s (1996) moral disengagement scale, and several scales from Stephens et al.'s (2007) Digital Technology and Academic Integrity Survey. While our work on this project is on-going and beyond the scope of this paper, those interested in learning more about our survey instrument can visit http://ethicsed.org/amis-survey.

\section{Methods}

\section{Participants and procedures}

Participants included 14 of 24 teachers (5 in NZ and 9 in the USA) who completed the teacher PD program and implemented the AwI-Seminar in their classrooms. Each of these teachers was observed while implementing two of the four Discussions of the AwI seminar with our built-for-purpose protocol described next. 
Measures

Based on the literature related fidelity of implementation (e.g., Carroll et al., 2007; Dusenbury, Brannigan, Falco, \& Hansen, 2003; James Bell Associates, 2009; Mihalic, 2004; O’Donnell, 2008), we developed measures to assess three distinct types of teacher participants' implementation fidelity of the AwI Seminar. Please see the Appendix for copy of this protocol.

Dosage

We used a single-item indicator of "dosage" (i.e., time, in minutes, per lesson) to assess the duration of program delivery in relation to the amount prescribed by the program (i.e., a minimum of $30 \mathrm{~min}$ per discussion/lesson).

Adherence

We developed a three-item measure of "adherence" to assess the extent to which program components were delivered as prescribed. Specifically, each lesson of the AwI Seminar has three major components - core questions, key concepts, and a primary activity protocol-and each component was coded as either absent (0) or present (1).

\section{Quality of delivery}

We developed a five-item scale of "quality of delivery" to assess the quality of the manner in which the AwI seminar was delivered by teachers. Specifically, we used a five-point Likert-type scale (where 1 = low and 5 = high) to rate the extent to which: 1 ) students were actively engaged in the discussion(s) related to the core question; 2) the teacher presented and described the key concepts and/or skills related to the core question; 3) students practiced using the concepts and/or skills being presented; 4) the lesson as a whole was clearly organized; and 5) the teacher demonstrated enthusiasm for topic during lesson.

\section{Results}

Among the 14 teachers who completed the PD program and implemented the AwI Seminar in their classrooms, the average dosage was $49.8 \mathrm{~min}$ (range $=33.5$ to 76.5), average adherence was $83.3 \%$ (range $=33.3$ to $100 \%$ ), and average quality of delivery was 3.68 (range $=2.50$ to 4.80 ). Mean scores for each measure as well as overall ratings by teacher are presented in Table 1.

\section{Discussion}

As detailed above, the results of this fidelity of implementation study were largely positive: teachers who implemented the AwI Seminar in their classrooms did so with a high degree of fidelity to the program's prescriptions and principles. Specifically, the dosage, adherence, and quality were all relatively high, on average. However, as indicated by the overall rating scores, the level of implementation fidelity was only high on average - one teacher earned a "poor" rating and three others earned only a "fair" rating. In short, the teacher PD program proved effective for most participants (10 of the 14), but insufficiently so for some teachers. This, of course, was a small-scale study and our works continues on improving not only the efficacy of the teacher PD program but also, and ultimately, its effectiveness on student outcomes.

\section{Summary and concluding thoughts}

The purpose of this paper was to describe a problem-based but possibility-driven approach to reducing academic dishonesty through the positive development of four components of moral functioning (Rest, 1986; Rest et al., 1999). More specifically, we described the FCM as a useful framework for 1) conceptualizing the problem of cheating as a function (and failure of one or 
Table 1 Mean scores from fidelity of implementation observations by Teacher

\begin{tabular}{llclcl}
\hline Teacher ID & Country & Dosage mean & Adherence mean & Quality of delivery mean & Overall Fol rating \\
\hline 111 & USA & 40.5 & $66.7 \%$ & 3.10 & $* *$ \\
112 & USA & 42.0 & $100.0 \%$ & 3.80 & $* * *$ \\
113 & USA & 33.5 & $66.7 \%$ & 2.50 & $*$ \\
312 & USA & 41.0 & $66.7 \%$ & 3.20 & $* *$ \\
313 & USA & 42.5 & $100.0 \%$ & 4.80 & $* * * *$ \\
121 & USA & 50.0 & $100.0 \%$ & 3.80 & $* * *$ \\
211 & USA & 76.5 & $83.3 \%$ & 3.50 & $* * *$ \\
212 & USA & 68.5 & $83.3 \%$ & 4.00 & $* * * *$ \\
213 & USA & 60.0 & $66.7 \%$ & 3.40 & $* * *$ \\
501 & NZ & 45.0 & $33.3 \%$ & 3.05 & $* *$ \\
601 & NZ & 50.0 & $100.0 \%$ & 4.80 & $* * * * *$ \\
602 & NZ & 50.0 & $100.0 \%$ & 4.10 & $* * * *$ \\
603 & NZ & 47.5 & $100.0 \%$ & 4.10 & $* * * *$ \\
604 & NZ & 50.0 & $100.0 \%$ & 3.30 & $* * *$ \\
& & 49.8 & $83 . \%$ & 3.68 & \\
\hline
\end{tabular}

Note: Fol fidelity of implementation

*poor, ${ }^{* *}$ fair, ${ }^{* * *}$ good, ${ }^{* * *}$ very good, ${ }^{* * * *}$ excellent

more) of four psychological processes (i.e., awareness, judgment, commitment, action) and 2) guiding the development of the AwI Seminar a possibility for promoting academic integrity (i.e., by increasing students' knowledge and skills associated with those four components).

In doing so, we hope to make a significant contribution to the research and intervention literature related to the problem of cheating. To date, the vast majority of the research literature on academic dishonesty is comprised of cross-sectional studies, focused on describing the nature of cheating as it exists. While such studies have been instrumental in helping us understand the extent of problem and its various correlates, there is a need to go beyond describing the problem and attempt to intervene and reduce it. Such experimental research is rare at present, but illustrates how relatively modest interventions can greatly reduce cheating behavior (e.g., Dee \& Jacob, 2010; Shu et al., 2011).

On a final note, while we adapted the FCM and developed the AwI Seminar with academic integrity as the focal problem, we believe the model and structure of the Seminar could be applied equally well to other sociomoral problems faced by adolescents. We were cognizant of this possibility when we developed the Seminar, and designed it accordingly_creating a framework of core questions, key concepts and activity protocols that can readily support the discussion of other important problems (e.g., bullying, stealing, lying, and illicit drug use). A quasi-experimental study of the Seminar's effectiveness is planned for implementation in the United States, and we are hopeful that it will prove effective in developing students' moral functioning related to academic integrity, If so, it seems likely that the Seminar might be useful in promoting similar results related to other challenging problems affecting our youth.

\section{Endnotes}

${ }^{1}$ For example, in their study of US and Canadian undergraduates, McCabe et al. (2012) found that $65 \%$ of students admitted to engaging in (in the past year) at least one of the nine behaviors surveyed; such as collaborating on an assignment when not permitted (42\%) and copying a few sentences in a paper without attribution (36\%). 


\section{Appendix}

Table 2 Observation protocol for Awl project

\begin{tabular}{|c|c|c|c|c|}
\hline & $\begin{array}{l}\text { Discussion } \\
\text { One }\end{array}$ & $\begin{array}{l}\text { Discussion } \\
\text { Two }\end{array}$ & $\begin{array}{l}\text { Discussion } \\
\text { Three }\end{array}$ & Discussion Four \\
\hline & $\begin{array}{l}\text { What's } \\
\text { moral? }\end{array}$ & What's right? & $\begin{array}{l}\text { Am I } \\
\text { responsible? }\end{array}$ & How do I do it? \\
\hline \multicolumn{5}{|l|}{ Dosage } \\
\hline \multicolumn{5}{|l|}{ Date } \\
\hline \multicolumn{5}{|l|}{ Start time } \\
\hline \multicolumn{5}{|l|}{ Stop time } \\
\hline \multicolumn{5}{|l|}{ Total minutes } \\
\hline Adherence & LoU (1 to 3) & LoU (1 to 3) & LoU (1 to 3) & LoU (1 to 3) \\
\hline Discussion of core questions & $\begin{array}{l}\text { What's } \\
\text { moral? } \\
\text { Is this a } \\
\text { moral } \\
\text { situation? }\end{array}$ & $\begin{array}{l}\text { What's right? } \\
\text { What should } \\
\text { one do? }\end{array}$ & $\begin{array}{l}\text { Am I } \\
\text { responsible? } \\
\text { Why be "good"? }\end{array}$ & $\begin{array}{l}\text { How do I do it? } \\
\text { What skills and } \\
\text { will are needed? }\end{array}$ \\
\hline \multicolumn{5}{|l|}{ Core question score } \\
\hline Instruction of key concepts & $\begin{array}{l}\text { Haidt's five } \\
\text { "Instuitive } \\
\text { Ethics" }\end{array}$ & $\begin{array}{l}\text { Three levels/ } \\
\text { lenses of } \\
\text { reasoning }\end{array}$ & $\begin{array}{l}\text { Mechanisms } \\
\text { of moral } \\
\text { disengagement }\end{array}$ & $\begin{array}{l}\text { Performance and } \\
\text { moral character } \\
\text { (Skill \& Will) }\end{array}$ \\
\hline \multicolumn{5}{|l|}{ Key concepts score } \\
\hline Use of Awl activity protocol & AMAP & EDMA & VIPA & SWAP \\
\hline \multicolumn{5}{|l|}{ Protocol score } \\
\hline Delivery & QoD (1 to 5) & QoD (1 to 5) & QoD (1 to 5) & QoD (1 to 5) \\
\hline \multicolumn{5}{|l|}{$\begin{array}{l}\text { Active engagement: The extent to } \\
\text { which students are actively engaged } \\
\text { in the discussion(s) related to the } \\
\text { core question. }\end{array}$} \\
\hline \multicolumn{5}{|l|}{$\begin{array}{l}\text { Providing information: The extent } \\
\text { to which the teacher presents and } \\
\text { describes the key concepts and/or } \\
\text { skills related to the core question. }\end{array}$} \\
\hline \multicolumn{5}{|l|}{$\begin{array}{l}\text { Procedural practice: The extent to } \\
\text { which students practice using the } \\
\text { concepts and/or skills being } \\
\text { presented (e.g., use of AMA.) }\end{array}$} \\
\hline \multicolumn{5}{|l|}{$\begin{array}{l}\text { Clarity of oraganization: The extent } \\
\text { to which the lesson as a whole is } \\
\text { clearly organized. }\end{array}$} \\
\hline $\begin{array}{l}\text { Positive affect: The extent which the teacher } \\
\text { demonstrates enthusiasm for topic during } \\
\text { lesson. }\end{array}$ & & & & \\
\hline
\end{tabular}

\section{Acknowledgements}

Both authors would like to thank the John Templeton Foundation, the Richard Davoud Donchian Foundation, and Wright Investors' Service for their encouragement and financial support. The opinions expressed in this paper are those of the authors and do not necessarily reflect the views of our funders. Finally, we thank the students, teachers, and administrators at the high schools that participated in this study. Without them, this project would not have been possible.

\section{Authors' contributions}

Both authors (JMS and DBW) developed the Awl Seminar and the teacher professional development program, and both authors were involved in the delivery and data collection associated with the latter. JMS developed the research 
design and conducted all data analyses, and wrote the first draft of the manuscript. DBW oversaw all project-related administrative responsiblities, and contributed to manuscript revisions. Both authors read and approved the final manuscript.

\section{Competing interests}

The authors declare that they have no competing interests.

\section{Author details}

${ }^{1}$ The University of Auckland, Auckland, New Zealand. ${ }^{2}$ The School for Ethical Education, Milford, CT, USA.

Received: 26 July 2016 Accepted: 6 October 2016

Published online: 26 October 2016

\section{References}

Anderman EM, Griesinger T, Westerfield G (1998) Motivation and cheating during early adolescence. J Educ Psychol 90(1):84-93

Anderman EM, Cupp PK, Lane D (2009) Impulsivity and academic cheating. J Exp Educ 78(1):135-150. doi:10.1080/ 00220970903224636

Bandura A (1986) Social Foundations of Thought and Action: A Social Cognitive Theory. Prentice-Hall, Englewood Cliffs Bandura A (1990) Selective activation and disengagement of moral control. J Soc Issues 46(1):27-46

Bandura A (1999) Moral disengagement in the perpetration of inhumanities. Personal Soc Psychol Rev 3(3):193-209

Bandura A, Barbaranelli C, Caprara C (1996) Mechanisms of moral disengagement in exercise of moral agency. J Pers Soc Psychol 71(2):364-374

Barnard, A., \& Newcomer, E. P. (2012). At Stuyvesant, Allegations of Widespread Cheating. The New York Times, A23. http://www.nytimes.com/2012/06/27/nyregion/looking-into-mass-cheating-via-text-message-at-stuyvesant. html?emc = tnt\&tntemail0 = y Retrieved from http://www.nytimes.com/2012/06/27/nyregion/looking-into-masscheating-via-text-message-at-stuyvesant.html?emc $=$ tnt\&tntemail $0=y$

Beck L, Ajzen I (1991) Predicting dishonest actions using the theory of planned behavior. J Res Pers 25(3):285-301 Benson PL, Scales PC, Hamilton SF, Sesma AJ (2006) Positive youth development so far: core hypotheses and their implications for policy and practice. Search Institute Insights Evidence 3(1):1-12

Berkowitz M, Sherblom S, Bier M, Battistich V (2006) Educating for positive youth development. In: Killen M, Smetana JG (eds) Handbook of Moral Development. Lawrence Erlbaum, Mahwah, pp 683-702

Bolin AU (2004) Self-control, perceived opportunity, and attitudes as predictors of academic dishonesty. J Psychol 138(2):101-114. doi:10.3200/jrlp.138.2.101-114

Bransford JD, Sherwood RD, Hasselbring TS, Kinzer CK, Williams SM (1990) Anchored instruction: Why we need it and how technology can help. In: Nix D, Spiro RJ (eds) Cognition, Education, and Multimedia: Exploring Ideas in High Technology. Erlbaum, Hillsdale

Carroll C, Patterson M, Wood S, Booth A, Rick J, Balain S (2007) A conceptual framework for implementation fidelity. Implement Sci 2:40

Damon W (2004) What is positive youth development? Ann Am Acad Pol Soc Sci 591:13-24

Dee TS, Jacob BA (2010) Rational Ignorance in Education: A Field Experiment in Student Plagiarism (Working Paper 15672). National Bureau of Economic Research. Retrieved from http://www.nber.org/papers/w15672

Diekhoff GM, LaBeff EE, Clark RE, Williams LE, Francis B, Haines VJ (1996) College cheating: Ten years later. Res High Educ 37(4):487-502

Dusenbury L, Brannigan R, Falco M, Hansen WB (2003) A review of research on fidelity of implementation: implications for drug abuse prevention in school settings. Health Educ Res 18(2):237-256. doi:10.1093/her/18.2.237

Grasmick HG, Tittle CR, Bursik RJ, Arneklev BJ (1993) Testing the core empirical implications of Gottfredson and Hirschi's general theory of crime. J Res Crime Deling 30:5-29

Haidt J (2001) The emotional dog and its rational tail: a social intuitionist approach to moral judgment. Psychol Rev 108(4):814-834

Haidt J (2013) Moral psychology for the twenty-first century. J Moral Educ 42(3):281-297. doi:10.1080/03057240.2013. 817327

Haidt J, Graham J (2007) When morality opposes justice: conservatives have moral intuitions that liberals may not recognize. Soc Justice Res 20(1):98-116. doi:10.1007/s11211-007-0034-z

Haidt J, Joseph C (2004) Intuitive ethics: How innately prepared intuitions generate culturally variable virtues. Daedalus 133(4):55-66. doi:10.1162/0011526042365555

Haines VJ, Diekhoff GM, LaBeff EE, Clark RE (1986) College cheating: immaturity, lack of commitment, and the neutralizing attitude. Res High Educ 25(4):342-354

Harding TS, Carpenter DD, Finelli CJ, Passow HJ (2004) Does academic dishonesty relate to unethical behavior in professional practice? An exploratory study. Sci Eng Ethics 10:311-324

Jackson PA (2006) Plagiarism instruction online: assessing undergraduate Students' ability to avoid plagiarism. College Res Libraries 67(5):418-428, Retrieved from http://crl.acrl.org/content/67/5/418.abstract

James Bell Associates. (2009). Evaluation brief: Measuring implementation fidelity. Retrieved from Arlington, VA: http:// www.jbassoc.com/ReportsPublications/Evaluation Brief - Measuring Implementation Fidelity_Octob\%E2\%80\%A6.pdf

Jensen LA, Arnett JJ, Feldman SS, Cauffman E (2002) It's wrong, but everybody does It: academic dishonesty among high school and college students. Contemp Educ Psychol 27(2):209-228, http://dx.doi.org/10.1006/ceps.2001.1088

Jordan AE (2001) College student cheating: the role of motivation, perceived norms, attitudes, and knowledge of institutional policy. Ethics Behav 11(3):233-247

Josephson Institute of Ethics (2012) 2012 Report Card on the Ethics of American Youth. Retrieved from https:// charactercounts.org/national-report-card/2012-report-card/ 
Kohlberg L (1969) Stage and Sequence: The Cognitive-Developmental Approach to Socialization. In: Goslin DA (ed) Handbook of Socialization Theory and Research. Rand McNally, Chicago, pp 347-480

Kohlberg L, Candee D (1984) The relationship of moral judgment to moral action. In: Kurtines WM, Gewirtz JL (eds) Morality, Moral Behavior, and Moral Development. Wiley, New York, pp 52-73

Leming JS (1978) Cheating behavior, situational influence, and moral development. J Educ Res 71(4):214-217

Lupton RA, Chapman KJ (2002) Russian and American college students' attitudes, perceptions and tendencies towards cheating. Educ Res 33(1):17-27

Ma Y, McCabe D, Liu R (2013) Students' academic cheating in Chinese universities: prevalence, influencing factors, and proposed action. J Academic Ethics 11(3):169-184. doi:10.1007/s10805-013-9186-7

Malinowski Cl, Smith CP (1985) Moral reasoning and moral conduct: an investigation prompted by Kohlberg's theory. J Pers Soc Psychol 49(4):1016-1027

Maxwell B, Beaulac G (2013) The concept of the moral domain in moral foundations theory and cognitive developmental theory: horses for courses? J Moral Educ 42(3):360-382. doi:10.1080/03057240.2013.818530

McCabe DL (1992) The influence of situational ethics on cheating among college students. Sociol Inq 62(3):365-374

McCabe DL (2005) Cheating among college and universtiy students: a North American perpspective. Int J Educ Integrity 1:1-11

Mihalic S (2004) The importance of implementation fidelity. Emotional Behav Disord Youth 4:83-86

Narvaez D (2009) Ethical Action Nurturing Character in the Classroom Series, EthEx Books 1-4, vol 4. Alliance for Catholic Education Press, South Bend

Narvaez D, Bock T (2009) Ethical Judgment Nurturing Character in the Classroom Series, EthEx Books 1-4, vol 2. Alliance for Catholic Education Press, South Bend

Narvaez D, Endicott LG (2009) Ethical Sensitivity Nurturing Character in the Classroom Series, EthEx Books 1-4, vol 1. Alliance for Catholic Education Press, South Bend

Narvaez D, Lies J (2009) Ethical Motivation Nurturing Character in the Classroom Series, EthEx Books 1-4, vol 3. Alliance for Catholic Education Press, South Bend

Narvaez D et al (2009) Nurturing Character in the Classroom Series, EthEx Books 1-4. Alliance for Catholic Education Press, South Bend

Nucci L (1994) Conceptions of personal issues: A domain distinct from moral or societal concepts. In: Puka B (ed) Fundamental Research in Moral Development. Garland, New York, pp 294-301

O'Donnell CL (2008) Defining, conceptualizing, and measuring fidelity of implementation and its relationship to outcomes in K-12 curriculum intervention research. Rev Educ Res 78(1):33-84. doi:10.3102/0034654307313793

Perez-Pena R, Bidgood J (2012) Harvard says 125 students yay have Cheated on a final exam. The New York Times. A18. Retrieved from http://www.nytimes.com/2012/08/31/education/harvard-says-125-students-may-have-cheatedon-exam.html?ref=harvarduniversity

Perry AR, Kane KM, Bernesser K, Spicker PT (1990) Type A behavior, competitive achievement-striving, and cheating among college students. Psychol Rep 66(2):459-465. doi:10.2466/pro.1990.66.2.459

Piaget J (1932) The Moral Judgment of the Child (M. Gabain, Trans.). Free Press, Glencoe

Quint, J. (2011). Professional development for teachers: What two rigorous studies tell us. Retrieved from http://www. mdrc.org/publications/603/overview.html.

Rawwas MYA, Al-Khatib JA, Vitell S (2004) Academic dishonesty: a cross-cultural comparison of US and Chinese marketing students. J Mark Educ 26:89-100

Rest JR (ed) (1986) Moral Development: Advances in Theory and Research. Praeger, New York

Rest JR, Narvaez D, Bebeau MJ, Thoma SJ (1999) Postconventional Moral Thinking: A neo-Kohlbergian Approach. Erlbaum, Mahwah

Schab F (1991) Schooling without learning: thirty years of cheating in high school. Adolescence 26:839-847

Shu LL, Gino F, Bazerman MH (2011) Dishonest deed, clear conscience: when cheating leads to moral disengagement and motivated forgetting. Personal Soc Psychol Bull 73(3):330-349

Shweder RA, Mahapatra M, Miller JG (1987) Culture and moral development. In: Kagan J, Lamb S (eds) The Emergence of Morality in Young Children. University of Chicago Press, Chicago, pp 1-83

Smetana JG (2006) Social-cognitive domain theory: Consistencies and variations in children's moral and social judgments. In: Killen M, Smetana JG (eds) Handbook of Moral Development. Erlbaum, Mahwah, pp 119-153

Stephens JM, Gehlbach HS (2007) Under pressure and under-engaged: Motivational profiles and academic cheating in high school. In: Anderman EM, Murdock TB (eds) Psychology of Academic Cheating. Academic, Amsterdam, pp 107-139

Stephens JM, Nicholson H (2008) Cases of incongruity: exploring the divide between adolescents' beliefs and behaviors related to academic cheating. Educ Stud 34(4):361-376

Stephens JM, Young MF, Calabrese T (2007) Does moral judgment go offline when students are online? A comparative analysis of undergraduates' beliefs and behaviors related to conventional and digital cheating. Ethics Behav 17(3): 233-254. doi:10.1080/10508420701519197

Stephens JM, Romakin V, Yukhymenko M (2010) Academic motivation and misconduct in two cultures: a comparative analysis of U.S. And Ukrainian undergraduates. Int J Educ Integrity 6(1):47-60

Sykes GM, Matza D (1957) Techniques of neutralization: a theory of delinquency. Am Sociol Rev 22:664-670

Turiel E (1983) The Development of Social Knowledge: Morality and Convention. Cambridge University Press, New York 